\title{
Increased difference between slow and forced vital capacity is associated with reduced exercise tolerance in COPD patients
}

\author{
Wei Yuan ${ }^{1}$, Xin He${ }^{1}$, Qiu-Fen Xu' ${ }^{1}$ Hao-Yan Wang ${ }^{1 *}$ and Richard Casaburi ${ }^{2}$
}

\begin{abstract}
Background: A higher slow vital capacity (VC) compared with forced vital capacity (FVC) indicates small airway collapse and air trapping. We hypothesized that a larger difference between VC and FVC (VC-FVC) would predict impaired exercise capacity in patients with chronic obstructive pulmonary disease (COPD).

Methods: Pulmonary function and incremental cardiopulmonary exercise responses were assessed in 97 COPD patients Patients were then divided into two groups: one in which VC > FVC $(n=77)$ and the other in which VC $\leq$ FVC $(n=20)$.

Results: Patients with VC > FVC had lower $\mathrm{FEV}_{1}$ and peak oxygen uptake $\left(\mathrm{VO}_{2} / \mathrm{kg}\right)$ compared with patients with $\mathrm{VC} \leq$ FVC. There was a significant inverse correlation for the entire group between $\mathrm{VC}-\mathrm{FVC}$ and peak $\mathrm{VO}_{2} / \mathrm{kg}(r=-0.404$; $p<0.001)$. There was also a direct correlation between $\mathrm{FEV}_{1} \%$ pred and peak $\mathrm{VO}_{2} / \mathrm{kg}(r=0.418 ; p<0.001)$. The results of the multivariate regression analysis with peak $\mathrm{VO}_{2} / \mathrm{kg}$ as the dependent variable showed that $\mathrm{VC}-\mathrm{FVC}$, FEV $1 \%$ pred) and age were all significant independent predictors of peak $\mathrm{VO}_{2} / \mathrm{kg}$. The model explained $35.9 \%$ of the peak $\mathrm{VO}_{2} / \mathrm{kg}$ variance.

Conclusions: The difference between VC and FVC, easily measured by spirometry, can be used not only as an index of severity of airflow limitation, but also to predict exercise performance in COPD patients.
\end{abstract}

Keywords: Chronic obstructive pulmonary disease, Spirometry, Exercise

\section{Backgrounds}

Persistent and progressive airflow limitation is a main characteristic of chronic obstructive pulmonary disease (COPD) [1]. As a result, patients with COPD experience dyspnea and impaired exercise capacity that progress over time. The disease severity has usually been graded based on the degree of airflow limitation, as measured by a reduced forced expiratory volume in one second $\left(\mathrm{FEV}_{1}\right)$. However, there is only a weak correlation between $\mathrm{FEV}_{1}$, symptoms and impairment of a patient's health-related quality of life [1]. The long-term rate of deterioration in exercise capacity in patients with COPD was found to be more rapid than the rate of decline in $\mathrm{FEV}_{1}$. The change in peak oxygen uptake $\left(\mathrm{VO}_{2}\right)$ over time was only weakly correlated with the change in $\mathrm{FEV}_{1}$ [2]. On the other hand, measurements of lung volumes, such

\footnotetext{
* Correspondence: haoyanw@126.com

'Department of Respiratory Medicine, Beijing Friendship Hospital, Capital Medical University, No. 95 Yong An Road, Xichen District, Beijing 100050, China
} Full list of author information is available at the end of the article as the inspiratory capacity (IC), correlate better with patient functional capabilities than do measurements of $\mathrm{FEV}_{1}$ [3-5].

IC has been wildly used to study pulmonary hyperinflation because it can be simply measured by spirometry. A low resting IC reflects pulmonary hyperinflation, which is defined as an abnormally increased lung volume at the end of tidal expiration and is present in moderate to severe COPD due to expiratory flow limitation and destructive changes of emphysema. Serial IC measurements have be used to track dynamic hyperinflation $(\mathrm{DH})$ during exercise, which occurs when ventilatory demand increases, leaving less time for expiration and resulting in air trapping within the lungs [6-8]. Several studies have showed that reduction in resting IC or dynamic IC constrains tidal volume expansion during exercise and contributes importantly to reduced exercise performance in patients with COPD $[6,7,9,10]$.

Vital capacity, simply measured by spirometry, is a lung volume measurement that can be measured as slow vital 
capacity (VC) or forced vital capacity (FVC). There is little or no difference between VC and FVC (VC-FVC) in normal subjects [11]. However, some studies have found that FVC is smaller than VC both in asthma patients and COPD patients and the difference between the two parameters is related to airflow limitation, small airway collapse and gas trapping [11-13].

We hypothesized that COPD patients with larger difference between VC and FVC would have lower exercise capacity. To test this hypothesis, we performed spirometry and cardiopulmonary exercise testing and examined the relationship of the difference between $\mathrm{VC}$ and FVC to exercise performance in patients with COPD.

\section{Methods}

\section{Subjects}

We recruited 97 patients with COPD who satisfied the following criteria: $\mathrm{FEV}_{1} / \mathrm{FVC}$ ratio $<0.7$ and $\mathrm{FEV}_{1}$ of 30 to $80 \%$ predicted after inhalation of $400 \mathrm{ug}$ albuterol [1] and in a stable condition for at least 6 weeks. Patients with diagnoses of interstitial lung disease or asthma were excluded. All patients received written and verbal information about the exercise testing. The study was approved by the Ethics Committee of Beijing Friendship Hospital.

\section{Pulmonary function tests}

Spirometry, including VC, FVC and $\mathrm{FEV}_{1}$ was performed using MasterScreen system (MasterScreen Body, CareFusion, Hoechberg, Germany) before exercise testing in all subjects. Procedures were carried out according to ATS/ERS standards [14]. VC was obtained by asking subjects to take in a full inspiration and then breathe out to the limit of full expiration in a relaxed manner except near end-inspiration and end-expiration. VC maneuvers was performed before FVC maneuvers, each of which was performed 3 times, with the highest value of each selected.

\section{Exercise testing}

Patients performed a progressive incremental exercise testing to a symptom-limited maximum on an electronically braked cycle ergometer (ViaSprint, CareFusion, Hoechberg, Germany). The protocol consisted of 3 minutes of rest, 3 minutes of unloaded pedaling, and minute-by-minute increments at a work rate of 5 to $20 \mathrm{~W} / \mathrm{min}$. Minute ventilation, oxygen uptake $\left(\mathrm{VO}_{2}\right)$, and carbon dioxide output $\left(\mathrm{VCO}_{2}\right)$ were acquired breath-by-breath using a computerized system (OxyconDelta, CareFusion, Hoechberg, Germany). Maximal heart rate (HR) predicted for age was calculated as 220-age [15].

\section{Statistical analysis}

Data with normal distribution are presented as means \pm SD and data not normally distributed are presented as median and interquartile range. Patients were classified into two groups using the difference between VC and FVC: one group with $\mathrm{VC}>\mathrm{FVC}$ and the other group with $\mathrm{VC} \leq \mathrm{FVC}$. Differences between the two groups were analyzed using independent sample t-tests. Comparison between the two groups in VC-FVC was performed using the MannWhitney U-test. Correlations between lung function and exercise variables were assessed by Pearson's correlation coefficient. A multivariate linear regression analysis was used to determine the independent association of lung function and other variables with exercise capacity. A $p$-value of less than 0.05 was considered statistically significant.

\section{Results}

Ninety seven patients with COPD were involved in this study. Of these, 4 patients were staged as mildly impaired (spirometry stage 1), 35 patients were moderately impaired (stage 2), 49 patients were severely impaired (stage 3), and 9 patients were very severely impaired (stage 4) according to GOLD classification [1]. The descriptive characteristics of the subjects are summarized in Table 1.

The patients were divided into those with $\mathrm{VC}>\mathrm{FVC}$ $(\mathrm{n}=77)$ and those with VC $\leq \mathrm{FVC}(\mathrm{n}=20)$. The lung function and exercise parameters of these two groups are shown in Table 2. The mean age was similar in the two groups. Patients with VC $>$ FVC had lower $\mathrm{FEV}_{1}$ and peak $\mathrm{VO}_{2} / \mathrm{kg}$ compared with patients with $\mathrm{VC} \leq \mathrm{FVC}$ (Figure 1). The peak work rate reached in the group of patients with $\mathrm{VC}>\mathrm{FVC}$ was lower than in the patients with $\mathrm{VC} \leq \mathrm{FVC}$, but without reaching statistical significance. There was no significant difference in heart rate at peak exercise between the two groups.

\section{Table 1 Patient characteristics}

\begin{tabular}{lc}
\hline Characteristics & Data \\
\hline Male & 97 \\
Age, yr & $64 \pm 8$ \\
Weight, kg & $70.37 \pm 10.68$ \\
VC, L & $2.72 \pm 0.72$ \\
FVC, L & $2.56 \pm 0.74$ \\
VC-FVC, $+\mathrm{L}$ & $0.11(0.02-0.24)$ \\
FEV $_{1}, \mathrm{~L}$ & $1.31 \pm 0.54$ \\
FEV $_{1}, \%$ predicted & $48.85 \pm 18.13$ \\
FEV $1 /$ FVC, $\%$ & $50.44 \pm 10.69$ \\
Peak VO, ml/min/kg & $14.45 \pm 4.92$ \\
Peak work rate, watts & $71.98 \pm 34.98$ \\
Peak HR, beats/min & $128 \pm 16$ \\
\hline
\end{tabular}

Data with normal distribution are presented as mean \pm SD.

†: Expressed as median (interquartile range).

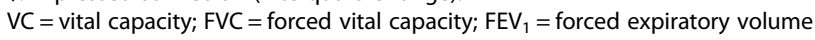
in one second; $\mathrm{VC}$-FVC = difference between VC and FVC; $\mathrm{VO}_{2}=$ oxygen uptake; $\mathrm{HR}=$ heart rate. 
Table 2 Lung function and exercise responses of patients with COPD classified by difference between VC and FVC

\begin{tabular}{lccc}
\hline & VC $>$ FVC & VC $\leq$ FVC & p-value \\
\hline Patients, $\mathrm{n}$ & 77 & 20 & \\
Age, $\mathrm{yr}$ & $65 \pm 8.2$ & $62 \pm 7.7$ & 0.187 \\
$\mathrm{VC} \mathrm{FVC}, \mathrm{L} \mathrm{L}$ & $0.16(0.07-0.27)$ & $-0.20(-0.30-0.03)$ & $<0.001$ \\
$\mathrm{FEV}_{1}, \mathrm{~L}$ & $1.21 \pm 0.46$ & $1.67 \pm 0.68$ & 0.008 \\
$\mathrm{FEV}_{1}, \%$ predicted & $46.41 \pm 16.13$ & $58.26 \pm 22.44$ & 0.009 \\
FEV $_{1} / \mathrm{FVC}, \%$ & $49.29 \pm 10.49$ & $54.89 \pm 10.54$ & 0.036 \\
Peak $\mathrm{VO}_{2}, \mathrm{ml} / \mathrm{min} / \mathrm{kg}$ & $13.26 \pm 3.92$ & $18.99 \pm 5.75$ & $<0.001$ \\
Peak work rate, watts & $68.53 \pm 34.45$ & $85.10 \pm 34.74$ & 0.059 \\
Peak HR, beats/min & $128 \pm 16$ & $128 \pm 11$ & 0.983 \\
\hline
\end{tabular}

Data with normal distribution are presented as mean $\pm S D$.

$t$ : Expressed as median (interquartile range).

$\mathrm{VC}=$ vital capacity; $\mathrm{FVC}=$ forced vital capacity $\mathrm{FEV}_{1}=$ forced expiratory volume in one second; $\mathrm{VC}-\mathrm{FVC}=$ difference between $\mathrm{VC}$ and $\mathrm{FVC}_{;} \mathrm{VO}_{2}=$ oxygen uptake; $\mathrm{HR}=$ heart rate.

There was a significant inverse correlation for the entire group between $\mathrm{VC}-\mathrm{FVC}$ and peak $\mathrm{VO}_{2} / \mathrm{kg}(\mathrm{r}=-0.404 ; \mathrm{p}<$ 0.001) (Figure 2). There was also a direct correlation between $\mathrm{FEV}_{1} \%$ pred and peak $\mathrm{VO}_{2} / \mathrm{kg}(\mathrm{r}=0.418 ; \mathrm{p}<0.001)$ (Figure 3).

The results of the multivariate regression analysis with peak $\mathrm{VO}_{2} / \mathrm{kg}$ as the dependent variable is presented in Table 3. Difference between VC and $\mathrm{FVC}, \mathrm{FEV}_{1} \%$ pred and age were all significant and independent predictors of peak $\mathrm{VO}_{2} / \mathrm{kg}$. The model explains $35.9 \%$ of the peak $\mathrm{VO}_{2}$ variance.

\section{Discussion}

In this study, patients with $\mathrm{VC}>\mathrm{FVC}$ had a lower $\mathrm{FEV}_{1}$ and a lower peak $\mathrm{VO}_{2} / \mathrm{kg}$, compared with those with

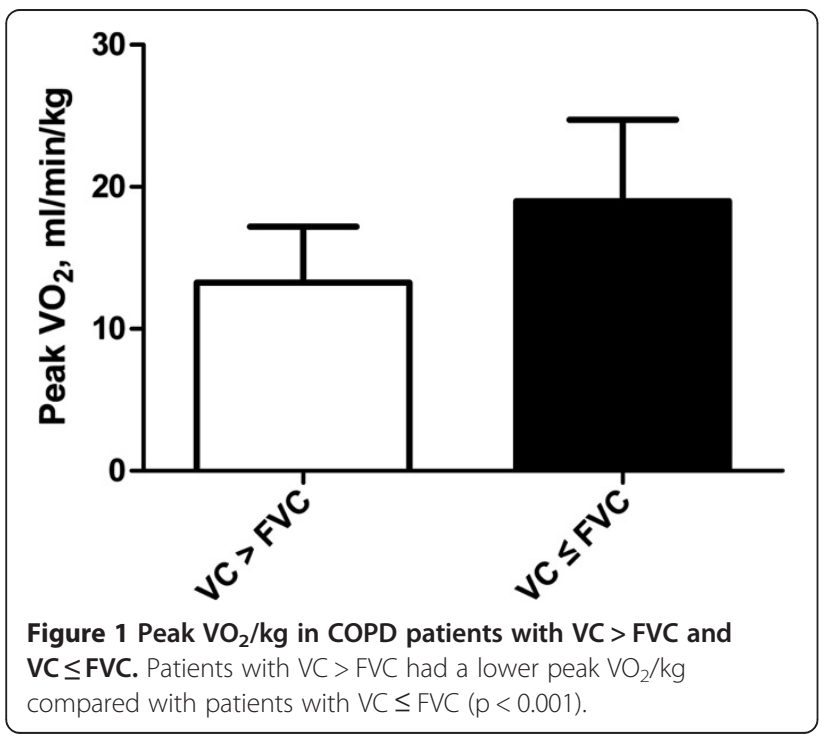

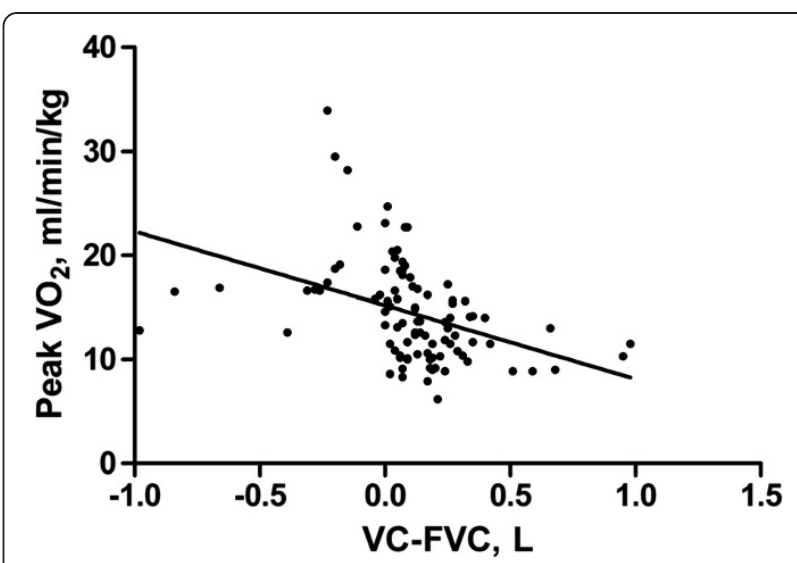

Figure 2 Relationship between VC-FVC and peak $\mathrm{VO}_{2} / \mathrm{kg}$. There was a significant inverse correlation for the entire group between VC-FVC and peak $\mathrm{VO}_{2} / \mathrm{kg}(r=-0.404 ; \mathrm{p}<0.001)$.

$\mathrm{VC} \leq \mathrm{FVC}$. There was a significant and inverse correlation for the entire group between $\mathrm{VC}-\mathrm{FVC}$ and peak $\mathrm{VO}_{2} / \mathrm{kg}$. There was also a direct correlation between $\mathrm{FEV}_{1} \%$ pred and peak $\mathrm{VO}_{2} / \mathrm{kg}$. The results of the multivariate regression analysis show that difference between $\mathrm{VC}$ and $\mathrm{FVC}$, $\mathrm{FEV}_{1} \%$ pred and age were significantly independent predictors of peak $\mathrm{VO}_{2} / \mathrm{kg}$. These results support our hypothesis that a larger difference between VC and FVC is associated with reduced exercise capacity in patients with COPD.

FVC is defined as the volume of air exhaled with maximal forced effort from a maximal inspiration. $\mathrm{VC}$ is similar to the FVC, but the maneuver is not forced and it is performed in a relaxed manner, except near the end-inspiration and end-expiration. Several studies have explored differences between $\mathrm{VC}$ and FVC and their

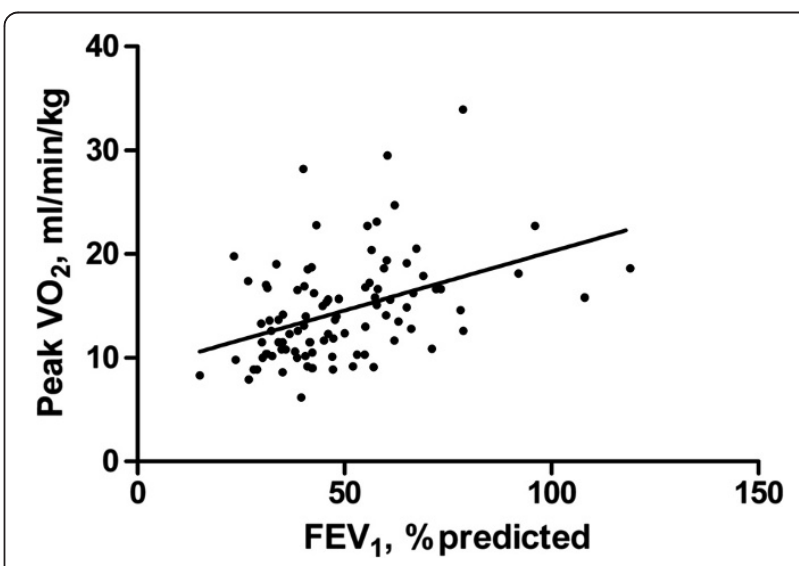

Figure 3 Relationship between $\mathrm{FEV}_{1}$, \% predicted and peak $\mathbf{V O}_{2} / \mathbf{k g}$. There was a direct correlation between $\mathrm{FEV}_{1} \%$ pred and peak $\mathrm{VO}_{2} / \mathrm{kg}(r=0.418 ; p<0.001)$. 
Table 3 Multivariate regression analysis in COPD patients with $\mathrm{VO}_{2}$ (in $\mathrm{ml} / \mathrm{min} / \mathrm{kg}$ ) at peak exercise as the dependent variable

\begin{tabular}{lcc}
\hline Independent variable & Coefficient & p-value \\
\hline Age, yr & -0.173 & 0.001 \\
FEV $_{1}, \%$ predicted & 0.098 & $<0.001$ \\
VC-FVC, L & -5.122 & 0.001 \\
\hline
\end{tabular}

$\mathrm{VC}$-FVC $=$ difference between $\mathrm{VC}$ and $\mathrm{FVC}_{;} \mathrm{FEV}_{1}=$ forced expiratory volume in one second.

relationship to small airway function. Cohen et al. [16] evaluated the $\mathrm{FVC} / \mathrm{VC}$ ratio in patients with bronchiolitis obliterans syndrome occurring after lung transplantation, in which small airways become progressively obliterated, leading to airway obstruction. They found that FVC/VC ratio decreased significantly with progressing bronchiolitis obliterans stages, which occurred independently of changes in $\mathrm{FEV}_{1}$. In asthma patients, it has been described that the difference between $\mathrm{VC}$ and $\mathrm{FVC}$ increases as the degree of obstruction increases. The difference can be used as an indicator of air trapping $[11,17]$. Similar results were found in the present study. We showed that $\mathrm{FEV}_{1} \%$ predicted was lower in patients with $\mathrm{VC}>\mathrm{FVC}$ than in those with $\mathrm{VC} \leq \mathrm{FVC}$, suggesting that difference between VC and FVC was significantly associated with the degree of airflow obstruction. There were 20 patients with $\mathrm{VC} \leq \mathrm{FVC}$. The underlying mechanism for larger FVC than $\mathrm{VC}$ remains uncertain.

Although VC and FVC are often measured in lung function laboratory, the difference between them has less been evaluated. To our knowledge, there have been no previous studies describing the relationship between the difference (VC-FVC) and exercise capacity in patients with COPD. The current study explored this relationship and showed that there was a significant and inverse correlation between VC-FVC and peak $\mathrm{VO}_{2} / \mathrm{kg}(\mathrm{r}=-0.404 ; \mathrm{p}<0.001)$. Combined with $\mathrm{FEV}_{1} \%$ predicted and age, the difference between VC and FVC could significantly account for $35.9 \%$ of the peak $\mathrm{VO}_{2} / \mathrm{kg}$ variance. This finding has an important implication for clinical practice. The difference between VC and FVC, simply measured by spirometry, can be used to predict exercise capacity in patients with COPD.

We may speculate on the underlying mechanism of association between the difference (VC-FVC) and exercise capacity. The first issue to consider is why a difference between VC and FVC exists in COPD. This has been explained by the following mechanism. Small airways, defined as those smaller than $2 \mathrm{~mm}$ in diameter, have no cartilaginous support and are subject to collapse when compressed [18]. During a slow VC maneuver, less thoracic gas compression occurs and greater air volume can be expired. In contrast, during an FVC maneuver, greater airway compression occurs and a smaller volume is expired. However, in healthy people this tendency is partly opposed by the attachment of the alveolar septa to the airway walls. In those with COPD, the airways tend to collapse during a forced expiration due to the reduction of alveolar attachments and airway abnormalities. Therefore, finding that VC is higher than FVC suggests small airway collapse and air trapping [17]. It further may indicate that static pulmonary hyperinflation is present. Since pulmonary hyperinflation constrains tidal volume expansion during exercise and contributes importantly to reduced exercise performance in patients with COPD, this seems a likely explanation for the association of the difference between VC and FVC and reduced exercise capacity in patients with COPD.

A limitation of the present study is that we did not measure inspiratory capacity during exercise, so as to better quantitate dynamic hyperinflation and more precisely reveal the mechanisms of association between $\mathrm{VC}$ FVC and exercise performance in patients with COPD. This should be addressed in future studies.

\section{Conclusion}

We have studied the association between VC, FVC and exercise capacity in patients with COPD. We found that the difference between VC and FVC at rest, which is easily obtained from spirometric results and does not depend on predicted population values, can be used not only as an index of severity of airflow limitation, but also to predict exercise performance in patients with COPD.

\section{Abbreviations \\ COPD: Chronic obstructive pulmonary disease; VC: Slow vital capacity; FVC: Forced vital capacity; VC-FVC: Difference between VC and FVC; $\mathrm{FEV}_{1}$ : Forced expiratory volume in one second; $\mathrm{VO}_{2}$ : Oxygen uptake; IC: Inspiratory capacity.}

\section{Competing interests}

The authors declare that they have no competing interests.

\section{Authors' contributions}

Conceptualization: HYW. Study design: HYW; QFX. Study implementation: WY; XH; QFX. Data analysis: HYW; WY. Manuscript preparation: HYW; RC. All authors read and approved the final manuscript.

\section{Funding}

This research was supported by grant Shou Fa 2011-2002-03 from Beijing Municipal Health Bureau.

\section{Author details}

${ }^{1}$ Department of Respiratory Medicine, Beijing Friendship Hospital, Capital Medical University, No. 95 Yong An Road, Xichen District, Beijing 100050, China. ${ }^{2}$ Rehabilitation Clinical Trials Center, Los Angeles Biomedical Research Institute at Harbor-UCLA Medical Center, Los Angeles, USA.

Received: 2 November 2013 Accepted: 5 February 2014

Published: 7 February 2014 
References

1. Global Initiative for Chronic Obstructive Lung Disease: Global strategy for diagnosis, management and prevention of COPD. (updated 2011). http:// www.goldcopd.com.

2. Oga T, Nishimura K, Tsukino M, et al: Exercise capacity deterioration in patients with COPD: Longitudinal evaluation over 5 years. Chest 2005, 128:62-69.

3. O'Donnell DE, Lam M, Webb KA: Spirometric correlates of improvement in exercise performance after anticholinergic therapy in chronic obstructive pulmonary disease. Am J Respir Crit Care Med 1999, 160:542-549.

4. O'Donnell DE, Voduc N, Fitzpatrick M, Webb KA: Effect of salmeterol on the ventilatory response to exercise in chronic obstructive pulmonary disease. Eur Respir J 2004, 24:86-94.

5. O'Donnell DE, Sciurba F, Celli B, Mahler DA, Webb KA, Kalberg CJ, Knobil K Effect of fluticasone propionate/salmeterol on lung hyperinflation and exercise endurance in COPD. Chest 2006, 130:647-656

6. Garcia-Rio F, Lores V, Mediano O, et al: Daily physical activity in patients with chronic obstructive pulmonary disease is mainly associated with dynamic hyperinflation. Am J Respir Crit Care Med 2009, 180:506-512.

7. O'Donnell DE, Revill SM, Webb KA: Dynamic hyperinflation and exercise intolerance in chronic obstructive pulmonary disease. Am J Respir Crit Care Med 2001, 164:770-777.

8. Ferguson GT: Why does the lung hyperinflate? Proc Am Thorac Soc 2006, 3:176-179.

9. Lammi MR, Ciccolella D, Marchetti N, Kohler M, Criner G: Increased oxygen pulse after lung volume reduction surgery is associated with reduced dynamic hyperinflation. Eur Respir J 2012, 40:837-843.

10. O'Donnell DE, Guenette JA, Maltais F, Webb KA: Decline of resting inspiratory capacity in COPD. Chest 2012, 141:753-762.

11. Chhabra SK: Forced vital capacity, slow vital capacity, or inspiratory vital capacity: which is the best measure of vital capacity. J Asthma 1998 35:361-365.

12. Brusasco V, Pellegrino A, Rodarte JR: Vital capacities in acute and chronic airway obstruction: dependence on flow and volume histories. Eur Respir $J$ 1997, 10:1316-1320.

13. O'Brien C, Guest PJ, Hill SL, et al: Physiological and radiological characterization of patients diagnosed with chronic obstructive pulmonary disease in primary care. Thorax 2000, 55:635-642.

14. Miller MR, Hankinson J, Brusasco V, et al: Standardisation of spirometry. Eur Respir J 2005, 26:319-338.

15. American Thoracic Society/American College of Chest Physicians: ATS/ACCP Statement on cardiopulmonary exercise testing. Am J Respir Crit Care Med 2003, 167:211-277.

16. Cohen J, Postma DS, Vin-Klooster K, et al: FVC to slow inspiratory vital capacity ratio, a potential marker for small airways obstruction. Chest 2007, 132:1198-1203.

17. Chan ED, Irvin CG: The detection of collapsible airways contributing to airflow limitation. Chest 1995, 107:856-859.

18. Levitzky MG: Pulmonary physiology. New York: McGraw-Hill; 1982:1-12.

doi:10.1186/1471-2466-14-16

Cite this article as: Yuan et al:: Increased difference between slow and forced vital capacity is associated with reduced exercise tolerance in COPD patients. BMC Pulmonary Medicine 2014 14:16

\section{Submit your next manuscript to BioMed Central and take full advantage of:}

- Convenient online submission

- Thorough peer review

- No space constraints or color figure charges

- Immediate publication on acceptance

- Inclusion in PubMed, CAS, Scopus and Google Scholar

- Research which is freely available for redistribution 